\title{
Differential response of vascular hepatocyte growth factor concentration and lipid accumulation between telmisartan and losartan in ApoE-deficient mice
}

\author{
HIRONORI NAKAGAMI ${ }^{1}$, MARIANA KIOMY OSAKO ${ }^{2}$, YOICHI TAKAMI $^{3}$, RIE HANAYAMA ${ }^{2}$, \\ HIROSHI KORIYAMA ${ }^{2}$, MASAKI MORI ${ }^{1}$, HIROKI HAYASHI ${ }^{1}$, HIDEO SHIMIZU ${ }^{2}$ and RYUICHI MORISHITA ${ }^{2}$ \\ Departments of ${ }^{1}$ Gene Therapy Science, ${ }^{2}$ Clinical Gene Therapy, ${ }^{3}$ Geriatric Medicine, \\ Osaka University Graduate School of Medicine, Osaka 565-0871, Japan
}

Received June 9, 2008; Accepted July 22, 2008

DOI: $10.3892 / \mathrm{mmr} 00000008$

\begin{abstract}
The favorable metabolic effects of telmisartan have been related to its blockade of angiotensin (Ang) II receptor and action as a partial agonist of peroxisome proliferatoractivated receptor $\gamma(\operatorname{PPAR} \gamma)$. We designed a comparative study of telmisartan and losartan in ApoE-deficient mice. ApoE-deficient mice were fed a high-fat diet with or without telmisartan $(10 \mathrm{mg} / \mathrm{kg} /$ day $)$ or losartan $(30 \mathrm{mg} / \mathrm{kg} / \mathrm{day})$ for 3 months. Treatment with telmisartan or losartan significantly reduced blood pressure, but did not affect serum cholesterol, triglyceride or glucose levels. Both drugs inhibited the development of lipid-rich plaque as assessed by oil red $\mathrm{O}$ staining. However, treatment with telmisartan, but not losartan, significantly improved endothelial dysfunction as assessed by the vasodilator response to acetylcholine. To elucidate the molecular mechanisms of the differential response in the improvement of endothelial dysfunction between telmisartan and losartan, we next focused on the expression of various cytokines. As both telmisartan and losartan attenuated interleukin-6 mRNA expression in the aorta, there was a significant change in endothelial nitric oxide synthase (eNOS) mRNA in the aorta. Notably, telmisartan, but not losartan, significantly increased the expression of hepatocyte growth factor (HGF), but not that of vascular endothelial growth factor (VEGF) in the aorta. Although a decrease in body weight and adipose tissue weight was observed with both telmisartan and losartan, liver weight was significantly decreased in only the telmisartan-treated group. Of importance, telmisartan markedly inhibited lipid accumulation in the liver. Overall, telmisartan and losartan induced differential responses in the improvement of endothelial dysfunction, probably due to their effects on
\end{abstract}

Correspondence to: Professor Ryuichi Morishita, Department of Clinical Gene Therapy, Osaka University Graduate School of Medicine, 2-2 Yamada-oka, Suita, Osaka 565-0871, Japan

E-mail: morishit@cgt.med.osaka-u.ac.jp

Key words: telmisartan, endothelial function, hepatocyte growth factor, apolipoprotein E, fatty liver vascular HGF levels and fatty liver. These favorable characteristics of telmisartan might be due to its action as a partial agonist of PPAR $\gamma$, beyond its blood pressure-lowering effect, through Ang II blockade.

\section{Introduction}

High blood pressure is closely associated with insulin resistance and dyslipidemia. Thus, current antihypertensive drugs should be designed to affect the cellular and biochemical mechanisms that contribute to an increase in blood pressure, and should also address the disordered lipid metabolism that often accompanies hypertension as part of the metabolic syndrome. Telmisartan, an angiotensin (Ang) type I receptor (AT1R) blocker (ARB), has been widely used in the treatment of hypertension and hypertension-related cardiovascular endorgan damage (1). When tested at concentrations that may be present in plasma with oral doses used for the treatment of hypertension, it was also identified as a unique moderately potent selective partial agonist of peroxisome proliferatoractivated receptor $\gamma(\operatorname{PPAR} \gamma)(2,3)$.

PPAR $\gamma$ plays an important role in regulating carbohydrate and lipid metabolism, and ligands for PPAR $\gamma$ can improve insulin sensitivity, reduce triglyceride (TG) levels and decrease the risk of atherosclerosis (4-6). A recent clinical study showed that in patients with type 2 diabetes and coronary artery disease, treatment with pioglitazone resulted in a significantly lower rate of progression of coronary atherosclerosis than treatment with glimapiride (7). Notably, telmisartan administration caused significant attenuation of weight gain and reduced glucose, insulin and TG levels in male SpragueDawley rats fed a high-fat, high-carbohydrate diet. It also improved insulin sensitivity in diet-induced obese mice without weight gain $(2,8)$, which might involve the inhibition of renin-angiotensin system activity and PPAR $\gamma$ activation. However, it is still unclear whether this unique Ang II receptor antagonist, telmisartan, would further protect against atherosclerosis beyond Ang II receptor blockade. In the present study, we compared the anti-atherosclerotic effects of telmisartan and losartan in ApoE-deficient mice with a high-fat sdiet to examine the additional effect of telmisartan beyond Ang II receptor blockade. 


\section{Materials and methods}

Animals and diets. Experiments were approved by the Ethics Committee for Animal Experiments of Osaka University Graduate School of Medicine. Male apolipoprotein E (ApoE)deficient mice of a C57/B16 background were obtained from Jackson Laboratory (Bar Harbor, ME). The mice (aged 8 weeks) were fed a normal diet (MF in Oriental Yeast) or a western diet [MF plus $0.5 \%$ (wt/wt) cholesterol and $10 \%$ yashi oil] with or without oral administration of telmisartan (10 mg/kg/day) or losartan (30 mg/kg/day) for 3 months. Mice had free access to water and food during the experimental periods.

At the end of the study, body weight and organ/tissue weights (heart, liver, kidney and adipose tissue) were measured, and a non-fasting terminal plasma sample was collected. Total cholesterol (T-Cho) was measured by a modification of the cholesterol oxidase method, while TG concentration was measured by a modification of the lipaseglycerol phosphate oxidase method.

Evaluation of lipid accumulation in the aorta and liver. Atherosclerotic lesion development was evaluated after 3 months of treatment. The thoracic descending and ascending aortae were removed from the heart and stained with oil red $\mathrm{O}$ after fixation with $4 \%$ paraformaldehyde. Stained aortae were opened longitudinally and pinned open. The percent of the intimal surface stained with oil red $\mathrm{O}$ in the arch and thoracic regions was measured morphometrically (WinRoof version 5.5, Mitani Corp., Japan). Cross sections of the aortae were also evaluated by hematoxylin and eosin (H\&E) staining and oil red $\mathrm{O}$ staining, as were liver samples after fixation with $4 \%$ paraformaldehyde.

Assessment of endothelial dysfunction. Endothelial function was assessed by evaluation of the vasodilator response to acetylcholine (ACh) (9). Briefly, the freshly isolated aortae were cut into $3-\mathrm{mm}$ rings, mounted in a $10-\mathrm{ml}$ organ bath containing Krebs-Henseleit buffer (KNB; $120 \mathrm{mmol} / \mathrm{l} \mathrm{NaCl}$, $4.7 \mathrm{mmol} / 1 \mathrm{KCl}, 2.5 \mathrm{mmol} / \mathrm{C} \mathrm{CaCl}_{2}, 1.2 \mathrm{mmol} / 1 \mathrm{MgSO}_{4}$, $1.2 \mathrm{mmol} / 1 \mathrm{KH}_{2} \mathrm{PO}_{4}, 25 \mathrm{mmol} / 1 \mathrm{NaHCO}_{3}, 5.5 \mathrm{mmol} / 1$ glucose, $\mathrm{pH} 7.4$ ), and maintained at $37^{\circ} \mathrm{C}$ oxygenated with $95 \% \mathrm{O}_{2}$, $5 \% \mathrm{CO}_{2}$. The aortic rings were equilibrated for $60 \mathrm{~min}$, with changes of bathing fluid every $15 \mathrm{~min}$. Isometric tension studies were performed using a transducer (TB-611T and AP-621G, Nihon Koden, Tokyo, Japan). Optimal resting tension was determined in baseline studies, then the response to vasoactive drugs was determined. Cumulative dose-response curves to ACh $\left(10^{-9}\right.$ to $\left.10^{-4} \mathrm{~mol} / \mathrm{l}\right)$ were established after the aortic rings were submaximally pre-contracted with phenylephrine $\left(10^{-5} \mathrm{~mol} / \mathrm{l}\right)$. Finally, the maximal relaxant response to papaverine $\left(10^{-4} \mathrm{~mol} / \mathrm{l}\right)$ was recorded. Endothelial function was also evaluated by means of vascular relaxation to sodium nitroprusside (SNP; $10^{-10}$ to $10^{-6} \mathrm{~mol} / \mathrm{l}$ ) after pretreatment with L-NAME $\left(10^{-4} \mathrm{mmol} / \mathrm{l}\right)$. Percent relaxation to several doses of ACh or SNP was calculated as the relative ratio to maximum relaxation (response to papaverine). $\mathrm{EC}_{50}$ values for Ach- and SNP-induced relaxation were calculated by non-linear least squares regression analysis (logistic regression, sigmoidal dose-response variable slope). ACh
Table I. Effects of telmisartan and losartan in ApoE-deficient mice.

\begin{tabular}{lccc}
\hline & High-fat diet & $\begin{array}{c}\text { High-fat diet } \\
+ \text { telmisartan }\end{array}$ & $\begin{array}{c}\text { High-fat diet } \\
+ \text { losartan }\end{array}$ \\
\hline SBP pre & $109 \pm 1$ & $104 \pm 2$ & $104 \pm 3$ \\
SBP 4W & $109 \pm 2$ & $96 \pm 2^{\mathrm{a}}$ & $98 \pm 4^{\mathrm{a}}$ \\
SBP 12W & $107 \pm 2$ & $84 \pm 2^{\mathrm{a}}$ & $90 \pm 2^{\mathrm{a}}$ \\
HR pre & $545 \pm 27$ & $510 \pm 35$ & $597 \pm 35$ \\
HR 4W & $636 \pm 24$ & $702 \pm 17^{\mathrm{a}}$ & $698 \pm 10^{\mathrm{a}}$ \\
HR 12W & $684 \pm 26$ & $690 \pm 17$ & $682 \pm 34$ \\
\hline
\end{tabular}

$\mathrm{SBP}$, systolic blood pressure $(\mathrm{mmHg})$; HR, heart rate (beats/min); pre, pre-treatment; $4 \mathrm{~W}, 4$ weeks after treatment; $12 \mathrm{~W}, 12$ weeks after treatment. ${ }^{a} \mathrm{p}<0.05$ vs. high-fat diet.

was obtained from Daichi Fine Chemical Co. Ltd. (Toyama, Japan), and other materials were obtained from Sigma (St. Louis, MO).

Real-time reverse transcription-polymerase chain reaction. The mRNA expression of murine endothelial nitric oxide synthase (eNOS), interleukin-6 (IL-6), hepatocyte growth factor (HGF) and vascular endothelial growth factor (VEGF) was measured by real-time reverse transcription polymerase chain reaction (RT-PCR). The total RNA of tissue samples was extracted using Isogen (Nippon Gene, Toyama, Japan). Complementary DNA was synthesized using the ThermoScript RT-PCR System (Invitrogen, Carlsbad, CA). Relative gene copy numbers of eNOS, IL-6, VEGF, HGF and glyceraldehyde-3-phosphate dehydrogenase (GAPDH) were quantified by real-time RT-PCR using TaqMan gene expression assays (murine eNOS, Hs00243522; murine IL-6, Hs00900360; murine HGF, Mm01135185; VEGF-A, Mm00437304; murine GAPDH, Mm99999915; Applied Biosystems, Foster City, CA). The absolute number of gene copies was normalized using GAPDH and standardized by means of a sample standard curve.

Statistical analysis. All values are expressed as the mean \pm SD. Data were compared using ANOVA followed by Dunnett's test for pair-wise comparisons against the control and by Tukey's test for multiple comparisons. All statistical analysis was performed using Stat-View 5.0 software (SAS Institute Inc., $\mathrm{NC}$ ). Values of $\mathrm{P}<0.05$ were considered to indicate statistical significance.

\section{Results}

Blood pressure, heart rate and plasma lipid profile. As shown in Table I, in ApoE-deficient mice fed a high-fat diet, treatment with telmisartan or losartan significantly reduced systolic blood pressure $(\mathrm{P}<0.01)$ and increased heart rate at 4 weeks $(\mathrm{P}<0.01)$. As for body and tissue weight, treatment with telmisartan or losartan resulted in a decrease in body weight and adipose tissue (epididymal, mesenteric, retroperitoneal) weight, but in no change in heart or kidney weight (Table II). Treatment with 
Table II. Effects of telmisartan and losartan on body ${ }^{\mathrm{a}}$ and organ weight ${ }^{\mathrm{b}}$

\begin{tabular}{lccc}
\hline & High-fat diet & $\begin{array}{c}\text { High-fat diet } \\
+ \text { telmisartan }\end{array}$ & $\begin{array}{c}\text { High-fat diet } \\
+ \text { losartan }\end{array}$ \\
\hline Pre BW & $25.3 \pm 1.4$ & $25.5 \pm 0.7$ & $25.6 \pm 0.6$ \\
Post BW & $35.0 \pm 2.3$ & $30.4 \pm 0.8^{\mathrm{c}}$ & $31.0 \pm 0.7^{\mathrm{c}}$ \\
Heart & $0.39 \pm 0.02$ & $0.37 \pm 0.01$ & $0.37 \pm 0.01$ \\
Liver & $5.44 \pm 0.21$ & $4.73 \pm 0.20^{\mathrm{c}}$ & $5.10 \pm 0.11$ \\
Kidney & $0.58 \pm 0.02$ & $0.60 \pm 0.03$ & $0.58 \pm 0.02$ \\
Adipose tissue & & & \\
$\quad$ Epididymal & $2.67 \pm 0.30$ & $1.98 \pm 0.26^{\mathrm{c}}$ & $1.87 \pm 0.23^{\mathrm{c}}$ \\
$\quad$ Mesenteric & $1.41 \pm 0.13$ & $1.14 \pm 0.16^{\mathrm{c}}$ & $0.99 \pm 0.09^{\mathrm{c}}$ \\
Retroperitoneal & $1.03 \pm 0.31$ & $0.80 \pm 0.14^{\mathrm{c}}$ & $0.69 \pm 0.07^{\mathrm{c}}$ \\
\hline
\end{tabular}

${ }^{\mathrm{a}}$ Measured in grams (g) and ${ }^{\mathrm{b}}$ in $\mathrm{g} / 100 \mathrm{~g}$ body weight (BW). ${ }^{\mathrm{c}} \mathrm{p}<0.05$ vs. high-fat diet.

Table III. Serum parameters in telmisartan- and losartantreated mice

\begin{tabular}{lccc}
\hline & High-fat diet & $\begin{array}{c}\text { High-fat diet } \\
+ \text { telmisartan }\end{array}$ & $\begin{array}{c}\text { High-fat diet } \\
+ \text { losartan }\end{array}$ \\
\hline GOT $^{\text {a }}$ & $83.7 \pm 10.7$ & $57.8 \pm 3.8^{\mathrm{a}}$ & $88.4 \pm 10.6$ \\
GPT $^{\mathrm{a}}$ & $32.8 \pm 3.9$ & $29.0 \pm 4.8$ & $27.6 \pm 2.4$ \\
T-Cho $^{\mathrm{b}}$ & $1335 \pm 140$ & $1350 \pm 100$ & $1312 \pm 27$ \\
LDL $^{\mathrm{b}}$ & $1188 \pm 107$ & $1229 \pm 66$ & $1249 \pm 23$ \\
HDL $^{\mathrm{b}}$ & $175 \pm 26$ & $231 \pm 17$ & $239 \pm 6$ \\
TG $^{\mathrm{b}}$ & $73 \pm 12$ & $69 \pm 16$ & $72 \pm 10$ \\
Glucose $^{\mathrm{b}}$ & $230 \pm 16$ & $228 \pm 9$ & $255 \pm 10$ \\
\hline
\end{tabular}

GOT, glutamate oxalacetate transaminase; GPT, glutamate pyruvate transaminase; T-Cho, total cholesterol;LDL, low-density lipoprotein; HDL, high-density lipoprotein; TG, triglyceride. ${ }^{a}$ Measured in IU/l and ${ }^{\mathrm{b}} \mathrm{mg} / \mathrm{dl} .{ }^{\mathrm{a}} \mathrm{p}<0.05 \mathrm{vs}$. high-fat diet.

telmisartan or losartan did not change plasma T-Cho, lowdensity lipoprotein, high-density lipoprotein, TG or glucose levels (Table III).

Effects of telmisartan and losartan on atherosclerosis, endothelial dysfunction and lipid deposition in the liver. We evaluated the development of lipid-rich plaque by oil red $\mathrm{O}$ staining. Treatment with telmisartan as well as losartan resulted in a significant reduction in the development of atherosclerosis (Fig. 1). However, while endothelial dysfunction was significantly improved by telmisartan (Fig. 2A) and induced by a high-fat diet, it was not affected by treatment with losartan (Fig. 2A). Similarly, treatment with telmisartan, but not losartan, significantly improved $\mathrm{EC}_{50}$, as shown in Fig. 2B. Results of the SNP challenge test, which was the quality control in this endothelial functional analysis, showed no significant differences between groups.

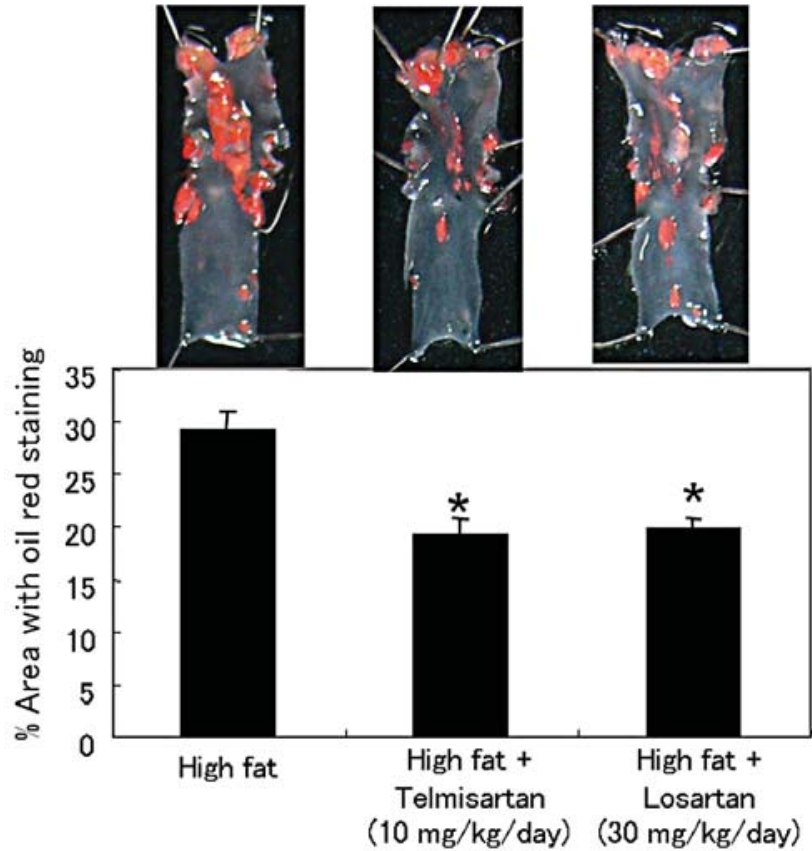

Figure 1. Atherosclerosis evaluated by oil red $\mathrm{O}$ staining in ApoE-deficient mice.The aorta was obtained from ApoE-deficient mice fed a high-fat diet with or without oral administration of telmisartan $(10 \mathrm{mg} / \mathrm{kg} /$ day $)$ or losartan $(30 \mathrm{mg} / \mathrm{kg} /$ day) for 3 months $(\mathrm{n}=8-9)$. The upper panel shows representative photomicrographs of oil red $\mathrm{O}$ staining in longitudinally opened aorta. The lower panel shows the percent of the intimal surface stained with oil red $\mathrm{O}$ (pink color). ${ }^{*} \mathrm{P}<0.01$ compared to high-fat diet.

To further clarify the mechanisms of the improvement of endothelial dysfunction by telmisartan, we focused on the mRNA expression of IL-6, an important inflammatory cytokine, and of eNOS, a key regulator of endothelial function, in the aorta. Treatment with telmisartan as well as losartan exhibited a significant decrease in IL-6 expression (Fig. 3A). Unexpectedly, telmisartan and losartan treatment resulted in no change in eNOS expression (Fig. 3B). Consequently, we went on to examine local expression of two important growth factors, VEGF and HGF, in the aorta. Telmisartan, but not losartan, significantly increased local vascular HGF expression, but not VEGF expression, in the aorta (Fig. 3C and D).

Notably, liver weight was only decreased by treatment with telmisartan, not with losartan (Table II). Glutamate oxalacetate transaminase was similarly decreased by treatment with telmisartan (Table III). Thus, we examined the condition of the liver by oil red $\mathrm{O}$ staining. Consistent with the above results, treatment with telmisartan markedly reduced lipid accumulation in the liver (Fig. 4).

\section{Discussion}

The present study demonstrated a differential response of endothelial dysfunction and lipid accumulation in the liver between telmisartan and losartan in ApoE-deficient mice with a high-fat diet, while both drugs inhibited the development of atherosclerosis, consistent with a previous report (10). These differences between telmisartan and losartan might be due to an increase in vascular HGF level. HGF is known to activate eNOS phosphorylation and increase NO production through the phosphoinositide 3-kinase/Akt pathway $(11,12)$. Moreover, previous reports have documented that HGF induced re- 
A

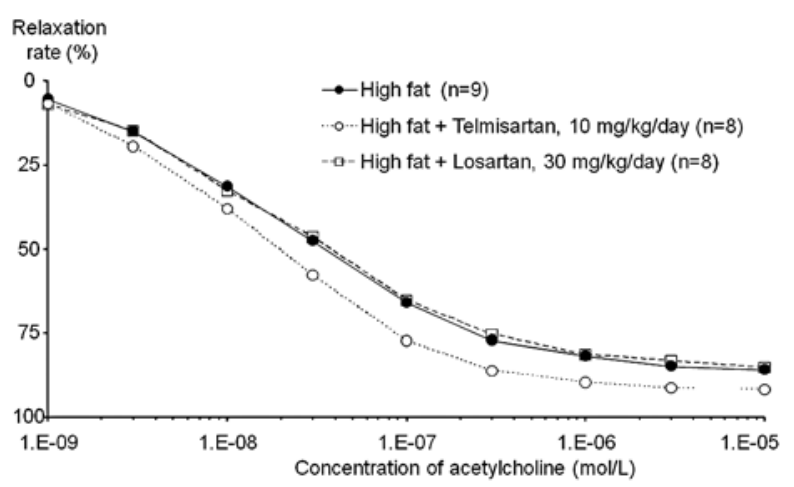

B

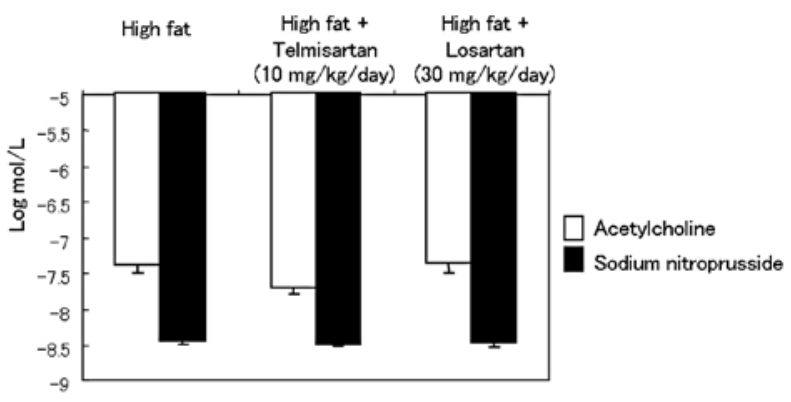

Figure 2. Endothelial function assessed by vasodilator response to acetylcholine (ACh). Aortae were obtained from ApoE-deficient mice fed a high-fat diet with or without oral administration of telmisartan $(10 \mathrm{mg} / \mathrm{kg} / \mathrm{day})$ or losartan $(30 \mathrm{mg} / \mathrm{kg} / \mathrm{day})$ for 3 months $(\mathrm{n}=8-9)$. (A) Percent vascular relaxation to $\mathrm{ACh}\left(10^{-9}\right.$ to $10^{-5} \mathrm{~mol} / \mathrm{l}$ ) in each group. (B) $\mathrm{EC}_{50}$ values for Ach- and sodium nitroprusside-induced relaxation calculated by nonlinear least squares regression analysis.
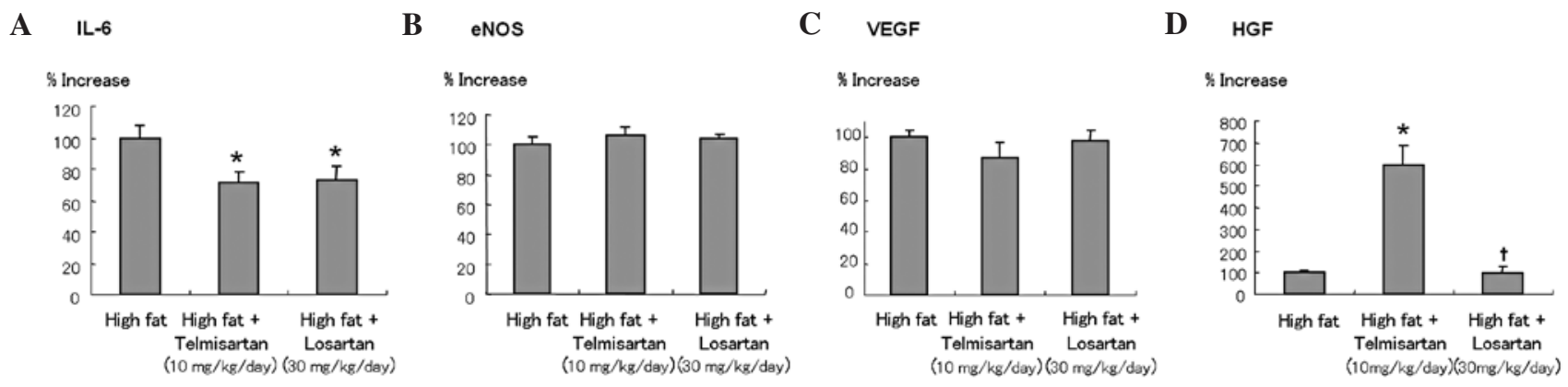

Figure 3. Quantification of (A) IL-6, (B) eNOS, (C) VEGF and (D) HGF mRNA expression in aortae by real-time PCR. Aortae were obtained from ApoEdeficient mice fed a high-fat diet with or without oral administration of telmisartan $(10 \mathrm{mg} / \mathrm{kg} / \mathrm{day})$ or losartan $(30 \mathrm{mg} / \mathrm{kg} / \mathrm{day})$ for $3 \mathrm{months}(\mathrm{n}=8-9)$. ${ }^{*} \mathrm{P}<0.01$ compared to high-fat diet, ${ }^{\dagger} \mathrm{P}<0.01$ compared to high-fat diet + telmisartan.
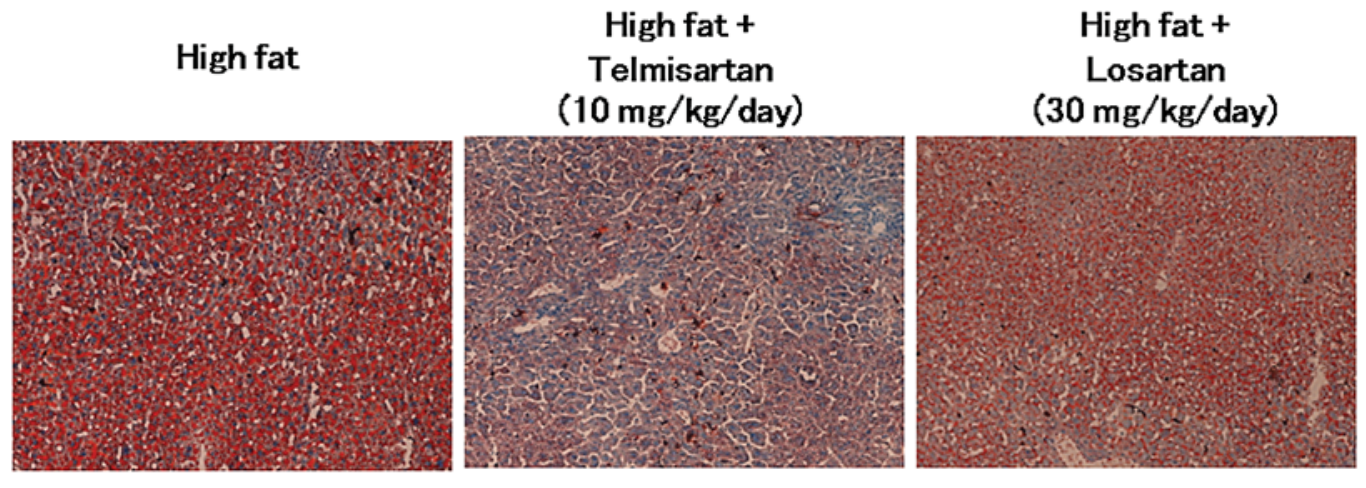

Figure 4. Lipid accumulation assessed by oil red $\mathrm{O}$ staining in the liver (x10 magnification). Livers were obtained from ApoE-deficient mice fed a high-fat diet with or without oral administration of telmisartan $(10 \mathrm{mg} / \mathrm{kg} /$ day $)$ or losartan $(30 \mathrm{mg} / \mathrm{kg} / \mathrm{day})$ for 3 months $(\mathrm{n}=8-9)$.

endothelialization (9), an anti-apoptotic effect (13) and therapeutic angiogenesis (14). In the regulation of the local vascular HGF system, it has been reported that hypoxia or hyperglycemia down-regulated HGF production, whereas the local HGF level might be inversely related to vascular damage (15-17). In contrast, Ang II is known to be a potent negative regulator (18). Therefore, the blockade of Ang II by an ARB might increase local HGF concentration. Indeed, vascular and cardiac HGF concentrations were increased by ARBs $(19,20)$. Nevertheless, the present study demonstrated that telmisartan, but not losartan, significantly increased vascular HGF levels.
One possible explanation for the differential actions of telmisartan is its unique ability to stimulate PPAR $\gamma$. In terms of cross-talk with HGF and PPAR $\gamma$, it has been reported that PPAR $\gamma$ binds to the putative peroxisome proliferator response element in the promoter region of the HGF gene, which leads to increased HGF gene transcription, mRNA expression, and protein secretion. Thus, HGF is considered to be a downstream effector in the anti-fibrotic action of PPAR $\gamma$ agonists (21). In this study, we observed that the up-regulation of HGF was induced only by telmisartan, probably through partial activation of PPAR $\gamma$, and speculate that HGF might be a down- 
stream molecule in the favorable action of PPAR $\gamma$ agonists in the vascular system. Although eNOS protein levels were not changed in each group, increased HGF may have contributed to the improvement of endothelial dysfunction. Thus, telmisartan might have dual effects, inducing local HGF expression through Ang II blockade and PPAR $\gamma$ activation.

Recent studies suggest that non-alcoholic steatohepatitis (NASH), which is characterized by varying degrees of progressive steatosis, lobular inflammation and fibrosis of the liver, is related to insulin resistance and metabolic syndrome $(22,23)$. In the development of NASH in a rat model, telmisartan as well as a PPAR $\gamma$ agonist, pioglitazone, markedly attenuated hepatic steatosis, inflammation and fibrosis (24). Importantly, the present study demonstrated that telmisartan, but not losartan, decreased lipid accumulation in the liver. These favorable effects of telmisartan might be mediated through its partial agonistic effect on PPAR $\gamma$, beyond Ang II receptor blockade. Indeed, telmisartan reduced the accumulation of visceral fat and decreased adipocyte size to a much greater degree than did valsartan, with a reduction in the hepatic TG level of rats (25). However, our results indicate that telmisartan as well as losartan significantly decrease fat and body weight in ApoE-deficient mice fed a high-fat diet. In addition, inhibition of the development of atherosclerosis, as assessed by lipid-rich plaque, and of inflammatory cytokine expression (IL-6 mRNA) occurred to a similar degree in both ARB-treated groups.

Overall, telmisartan and losartan demonstrated differential responses in the improvement of endothelial dysfunction, probably due to their effects on vascular HGF levels and fatty liver. These favorable characteristics of telmisartan might be due to its action as a partial agonist of PPAR $\gamma$, beyond its blood pressure-lowering effect through Ang II blockade. Upregulation of local HGF by telmisartan through PPAR $\gamma$ activation might provide a novel advantage in strategies for the prevention and treatment of cardiovascular disease.

\section{Acknowledgements}

This work was supported by a grant-in-aid from the Ministry of Education, Culture, Sports, Science and Technology of Japan and by a Japan Heart Foundation Grant for Research.

\section{References}

1. De Gasparo M, Catt KJ, Inagami T, Wright JW and Unger T: International Union of Pharmacology. XXIII. The angiotensin II receptors. Pharmacol Rev 52: 415-472, 2000.

2. Benson SC, Pershadsingh HA, Ho CI, et al: Identification of telmisartan as a unique angiotensin II receptor antagonist with selective PPARgamma-modulating activity. Hypertension 43: 993-1002, 2004.

3. Schupp M, Janke J, Clasen R, Unger T and Kintscher U: Angiotensin type 1 receptor blockers induce peroxisome proliferator-activated receptor-gamma activity. Circulation 109: 2054-2057, 2004.

4. Lehmann JM, Moore LB, Smith-Oliver TA, Wilkison WO, Willson TM and Kliewer SA: An antidiabetic thiazolidinedione is a high affinity ligand for peroxisome proliferator-activated receptor gamma (PPAR gamma). J Biol Chem 270: 12953-12956, 1995.
5. Rosen ED and Spiegelman BM: PPARgamma: a nuclear regulator of metabolism, differentiation, and cell growth. J Biol Chem 276: 37731-37734, 2001.

6. Picard F and Auwerx J: PPAR(gamma) and glucose homeostasis. Annu Rev Nutr 22: 167-197, 2002.

7. Nissen SE, Nicholls SJ, Wolski K, et al: Comparison of pioglitazone vs glimepiride on progression of coronary atherosclerosis in patients with type 2 diabetes: the PERISCOPE randomized controlled trial. JAMA 299: 1561-1573, 2008.

8. Schupp M, Clemenz M, Gineste R, et al: Molecular characterization of new selective peroxisome proliferator-activated receptor gamma modulators with angiotensin receptor blocking activity. Diabetes 54: 3442-3452, 2005.

9. Hayashi K, Nakamura S, Morishita R, et al: In vivo transfer of human hepatocyte growth factor gene accelerates reendothelialization and inhibits neointimal formation after balloon injury in rat model. Gene Ther 7: 1664-1671, 2000.

10. Takaya T, Kawashima S, Shinohara M, et al: Angiotensin II type 1 receptor blocker telmisartan suppresses superoxide production and reduces atherosclerotic lesion formation in apolipoprotein E-deficient mice. Atherosclerosis 186: 402-410, 2006.

11. Uruno A, Sugawara A, Kanatsuka H, et al: Hepatocyte growth factor stimulates nitric oxide production through endothelial nitric oxide synthase activation by the phosphoinositide 3-kinase/Akt pathway and possibly by mitogen-activated protein kinase kinase in vascular endothelial cells. Hypertens Res 27: 887-895, 2004.

12. Makondo K, Kimura K, Kitamura N, et al: Hepatocyte growth factor activates endothelial nitric oxide synthase by $\mathrm{Ca}(2+)$ - and phosphoinositide 3-kinase/Akt-dependent phosphorylation in aortic endothelial cells. Biochem J 374: 63-69, 2003.

13. Nakagami H, Morishita R, Yamamoto K, et al: Hepatocyte growth factor prevents endothelial cell death through inhibition of bax translocation from cytosol to mitochondrial membrane. Diabetes 51: 2604-2611, 2002.

14. Taniyama Y, Morishita R, Aoki M, et al: Therapeutic angiogenesis induced by human hepatocyte growth factor gene in rat and rabbit hindlimb ischemia models: preclinical study for treatment of peripheral arterial disease. Gene Ther 8: 181-189, 2001.

15. Nakamura S, Morishita R, Moriguchi A, et al: Hepatocyte growth factor as a potential index of complication in diabetes mellitus. J Hypertens 16: 2019-2026, 1998.

16. Morishita R, Nakamura S, Nakamura Y, et al: Potential role of an endothelium-specific growth factor, hepatocyte growth factor, on endothelial damage in diabetes. Diabetes 46: 138-142, 1997.

17. Hayashi S, Morishita R, Nakamura S, et al: Potential role of hepatocyte growth factor, a novel angiogenic growth factor, in peripheral arterial disease: downregulation of HGF in response to hypoxia in vascular cells. Circulation 100: II301-II308, 1999.

18. Taniyama Y, Morishita R, Nakagami H, et al: Potential contribution of a novel antifibrotic factor, hepatocyte growth factor, to prevention of myocardial fibrosis by angiotensin II blockade in cardiomyopathic hamsters. Circulation 102: 246-252, 2000.

19. Nakano N, Moriguchi A, Morishita R, et al: Role of angiotensin II in the regulation of a novel vascular modulator, hepatocyte growth factor (HGF), in experimental hypertensive rats. Hypertension 30: 1448-1454, 1997

20. Nakano N, Morishita R, Moriguchi A, et al: Negative regulation of local hepatocyte growth factor expression by angiotensin II and transforming growth factor-beta in blood vessels: potential role of HGF in cardiovascular disease. Hypertension 32: 444-451, 1998.

21. Li Y, Wen X, Spataro BC, Hu K, Dai C and Liu Y: Hepatocyte growth factor is a downstream effector that mediates the antifibrotic action of peroxisome proliferator-activated receptorgamma agonists. J Am Soc Nephrol 17: 54-65, 2006.

22. Angulo P: Nonalcoholic fatty liver disease. N Eng J Med 346: 1221-1231, 2002.

23. Angulo P: Obesity and nonalcoholic fatty liver disease. Nutr Rev 65: S57-S63, 2007.

24. Fujita K, Yoneda M, Wada K, et al: Telmisartan, an angiotensin II type 1 receptor blocker, controls progress of nonalcoholic steatohepatitis in rats. Dig Dis Sci 52: 3455-3464, 2007.

25. Sugimoto K, Qi NR, Kazdova L, Pravenec M, Ogihara T and Kurtz TW: Telmisartan but not valsartan increases caloric expenditure and protects against weight gain and hepatic steatosis. Hypertension 47: 1003-1009, 2006. 